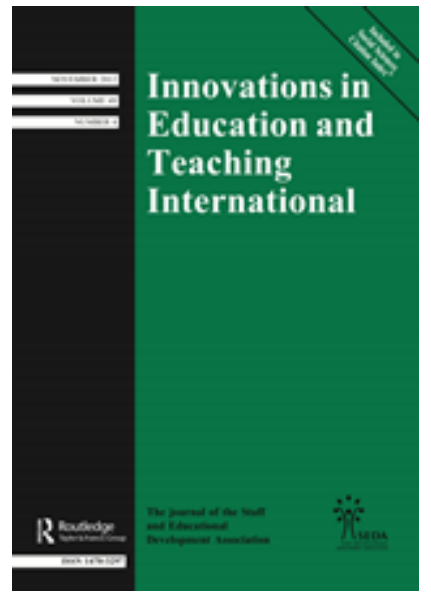

\title{
Exploring the professional development of online and distance doctoral supervisors
}

\begin{tabular}{|r|l|}
\hline Journal: & Innovations in Education and Teaching International \\
\hline Manuscript ID & RIIE-2019-0389.R2 \\
\hline Manuscript Type: & Original Article \\
\hline Areas of Interest: Keywords: & $\begin{array}{l}\text { doctoral supervision, distance and online supervision, professional } \\
\text { development, adult learning, supervisor development }\end{array}$ \\
\hline
\end{tabular}

\section{SCHOLARONE Manuscripts}




\title{
Exploring the professional development of online and distance doctoral supervisors
}

\begin{abstract}
The supervision of doctoral students has been evolving in the last decade. Supervisors supervise students on campus or at a distance and supervision takes place in formal or informal environments with the latter occurring more often through online encounters. This context of supervision has changed supervisory practices and students' own approaches to learning. This paradigmatic shift demands a rethinking of how supervisors develop themselves and how they learn to cope with the challenges of 'modern' supervision. To date, little has been said or written about the development or training of doctoral supervisors who supervise students online or at a distance. This paper aims to fill this gap by presenting a model for the professional development of supervisors in these contexts. This model can be adapted and implemented by institutions that wish to support supervisors who support students online or at the distance.
\end{abstract}

Keywords: doctoral supervision, distance and online supervision, professional development

\section{Introduction}

In the UK, the USA and Australasia there has been an exponential growth in online doctoral education, which is especially targeted at non-traditional students, such as working professionals, part-time students and adult learners who cannot come to the campus regularly (Albion \& Erwee, 2011). These programmes also have higher attrition rates (Albion \& Erwee, 2011; Ames et al., 2018), which require institutions to address the multidimensional factors that contribute to attrition, such as students feeling a sense of depersonalization and isolation, and the lack of collaborative learning environments (Ames et al., 2018). Arguably, online or distance supervision inevitably affects the way supervisors and students work, as well as their expectations, roles and responsibilities. This paradigmatic shift demands a rethinking of supervisory practices and the 
reconfiguration of the existing learning environments/spaces. In this context, it is urgent to rethink the professional development of supervisors, who, at some stage in the supervisor journey, need to supervise students online and at a distance.

Little has been said or written on the development or training of supervisors for online or distance supervision. Most of the literature on the subject explores the role of, or approaches to supervision that takes place in more 'traditional' environments (Halse \& Malfroy, 2010), where supervision occurs mainly in face-to-face (f2f) encounters and where the student is physically located in the university. For this paper, we define distance doctoral supervision as a supervision process characterised by the research student and supervisor or tutor working at a distance mediated by learning technologies. The supervision is mediated by virtual learning environments where students and supervisors rely on technology to communicate or build communities of practice, involving greater connectedness, collaboration and more intense relationships between themselves (Maor \& Currie, 2017) or within the wider academic community (Loureiro, et al., 2010).

Although there is increasing demand for distance doctoral studies, educational research is raising questions about the quality and challenges of distance supervision (Erichsen et al., 2014; Nasiri \& Mafakheri, 2015), and the training of supervisors (Halse \& Malfroy, 2010; Spiller et al., 2013).

In this conceptual paper, we intend to explore the topic of distance research supervision and the challenges that supervisors face in their supervisory practices, as well as the theoretical foundations of adult learning theories, and provide a model for the professional development of distance doctoral supervisors.

\section{Distance research supervision}

Doctoral supervision is a traditional role in the profession, typically supported by the 'passing of the torch' method, which leads to supervision wisdom and is typically conducted intuitively by professors who mentor their $\mathrm{PhD}$ students in an apprenticeship model (Maor et al., 2016). Scholars often work collaboratively as part of research teams 
and, within their day-to-day routine, share their methods, findings and research outputs with their supervisors and fellow colleagues. Traditional supervision is done in a one-toone relationship and in $\mathrm{f} 2 \mathrm{f}$ environments, albeit with an important community element between fellow researchers.

However, those working synergies have been challenged by the emergence of non-traditional doctorates targeted at non-traditional students, as referred to in the introduction. These doctorates can include accelerated programmes or professional doctorates delivered through blended learning or flexible scheduling, or fully at a distance (Singleton \& Session, 2011). In this context technologies play a major role since they have become the vehicle for teaching and supervision. Technology is already having an impact on how doctoral research is conducted, whether on campus or at a distance, which is causing a set of challenges.

The first challenge in distance doctoral supervision is driven by space and temporal distance. The supervisor and supervisee may live on different continents and in different time zones, which may create issues with finding mutually convenient times to meet (Nasiri \& Mafakheri, 2015; Wisker et al., 2007) and even lead to a feeling of isolation or sense of loneliness for both parties. This feeling of isolation may lead to a lack of focus, disconnectedness, a feeling of being unsupported, and too much reliance on the supervisor (Bolliger et al., 2010), contradicting a key objective of most postgraduate research, which is to promote 'independent research and critical thinking' (Nasiri \& Mafakheri, 2015, p. 1965). This leads us to a second challenge, which is management of expectations and communication (Ames et al., 2018). As a result of the detachment caused by the distance it is likely that the supervisor will not know the supervisee before the supervision process starts and thus there is a strong need for further informal conversations to ensure that the environment is conducive to meaningful encounters. The challenge is therefore to create an environment where students can safely interact with their fellow students, agree methods of distance communication, and clarify forms of communication and learning expectations. This is essential for building trusting relationships, marked by high levels of professionalism. The communication challenges are often mitigated by increasing the number of videoconferencing meetings and the amount of individual support and by improving the community support aspects of the programme. The importance of developing online 
supervision communities has been strongly advocated by authors such as Crosta et. al (2015) and Wikeley and Muschamp (2004).

A third challenge relates to culture and language diversity. Distance learning cohorts are typically more diverse in terms of nationalities, cultures, religions and languages so there is an expectation that there will be some language and cultural barriers. Wisker, et al. (2007) argue that when not properly addressed, those cultural barriers may trigger misinterpretation and potentially clashes between the supervisor and the supervisee.

In summary, it is crucial for supervisors to understand the challenges, problems and pedagogical implications of working with doctoral students online or at a distance in order to build structures that support effective interactions and supervisor-supervisee relationships in virtual encounters (Roumell \& Bolliger, 2017) and create connectedness between the distance doctoral student and the research community (Maor et al., 2016). Current supervisors may never have experienced distance supervision or may have limited digital skills to work in and through virtual learning environments (Singleton \& Session, 2011) with students they have never met in person, and therefore require 'support in developing the range of skills appropriate to supervising doctoral students at a distance' (Albion \& Erwee, 2011, p.84). The traditional mode of supervision is being replaced by a new one that few have experienced or are comfortable with. The challenges presented here set the ground for the need for the professional development of supervisors, who must learn how to cope with these challenges.

\section{Professional development: Theoretical foundations}

The purpose of professional development is to instigate learning. In Marsick's words, 'learning is the way in which individuals or groups acquire, interpret, reorganize, change or assimilate a related cluster of information, skills and feelings' (Marsick, 1988, p. 88). It is also primary to the way in which 'people construct meaning in their personal and shared organizational lives' (p. 88). Many studies written in the 1980s reveal that a large percentage of learning takes place on-the-job rather than through formal training (Kaplan et al., 1985). However, formalising learning is also important, as it provides structure and 'space' for academics to reflect and have discussions with each other. 
The model we propose is grounded in the theories of adult education and organisational learning such as Mezirow's transformative learning theory (1981), Halse and Malfroy's professional work facets (2010) and Lave and Wenger's work on Communities of Practice (CoP) and situated learning (1991) because these represent how learning should take place in the workplace. We believe that distance supervisors should learn in their professional settings by engaging with both formal and informal learning and by having the opportunity to reflect on and discuss their work with their peers in a community of practice. Learning occurs when supervisors change or shape, for example, their own approaches to supervision or support student work. These are important elements of the theories presented below.

\section{Transformative learning theory}

The transformative learning theory accounts for the need to develop professional skills that are intertwined with organisational learning and self-reflection, as well as different forms of workplace learning, which are implicit and informal or situated and formal (Evans, 2018; Sawyer, 2002). According to Evans (2018), informal learning occurs when participants engage with 'forms of professional learning and development that are not explicitly labelled or signposted as such' (p. 6). Formal learning, on the other hand, is more explicit and usually takes place through formal training.

Mezirow (1981) identified three types of learning, Instrumental, Dialogic and Selfreflective, that should be considered in any form of professional development.

Instrumental learning refers to task-oriented problem solving, with a focus on technical learning where reflection is usually that of single cause-effect as in single-loop learning (Marsick \& Watkins, 2015). In this case, supervisors identify a problem, formulate a hypothetical course of action, try it out, observe the effects and evaluate the results. Learning is prescriptive and usually takes place in formal learning environments such as workshops and seminars.

Dialogic learning takes place in work settings where learners have the opportunity to question organisational norms and assumptions. Reflection is carried out 
critically as in double-loop learning - learning includes active questioning about previously held beliefs or information.

Self-reflective learning is the way in which we learn to understand ourselves and is directed at personal change. The focus is on the development of supervisors' identity and role, and the need for self-change. Instrumental, dialogic and self-reflective learning cannot be easily separated and should be considered in terms of how academics learn in their professional settings.

\section{'Professional work' facets}

Halse \& Malfroy (2010) theorised the doctoral supervision process as professional work and, based on empirical analyses, developed a framework for the supervisory process. Labels were assigned to each facet to capture the substantive and theoretical features of the data in the following categories:

1. The learning alliance is the agreement between the supervisor and the student to work on a common goal, namely the production of a high-quality doctorate; in a distance education setting expectations are particularly relevant while negotiating goals and tasks. Here distance supervisors are expected to discuss how to reach a consensus and overcome barriers for timely completion.

2. Habits of mind refer to both a disposition and a mode of behaviour. They involve the capacity to learn and reflect on the principles for making particular decisions, and to exercise the judgment and disposition to apply these principles in unfamiliar or unforeseen situations in ethically appropriate ways. Habits of mind are necessary to ensure that supervisors are open to supervising and practising vivas and mock vivas in 'third spaces' and are willing to move away from their comfort zone in terms of supervision and $\mathrm{PhD}$ examinations.

3. Scholarly expertise is central to the work of doctoral supervision. Scholarly expertise, in this context, is the theoretical knowledge acquired through reflection and thinking. In this domain, it is important for supervisors to develop their knowledge around the context of distance doctoral education; theories of, and approaches to supervision; the role of both the supervisor and the 
supervisee; distance learning theories; research ethics; and feedback on students' work.

4. Technê comprises the craft knowledge - technical skills or instrumental practice - and the creative, productive use of expert knowledge to bring something into existence or accomplish a particular objective. Within the supervisory process, this knowledge can be combined in three areas: (i) what technical competencies and skills are needed by the students; (ii) when it is appropriate to use these skills; and (iii) why these skills are important; and the capacity to communicate these reasons to students.

5. Contextual expertise comprises an understanding of the contemporary climate of universities in relation to doctorates and doctoral education; the 'know- how' regarding access to the infrastructure and resources needed by students; a knowledge of faculty and university policies, procedures and requirements for each stage of the candidature; an understanding of the tensions between different approaches and methods in the production of a doctorate; and the capacity to advise students on how to traverse this complex territory.

These five facets are important key competencies in supervisors' development and should be included in any professional development course for distance supervisors.

\section{Communities of practice}

Communities of practice have been widely used in the professional development of academic staff and specifically supervisors (Hill \& Vaughan, 2018; Wisker et al., 2007). Communities of practice have been defined as groups of people who share a passion for certain topics and for deepening their expertise and knowledge through continuous interaction (Lave \& Wenger, 1991). A community of practice entails three key elements: the domain (the topic that unites the community), the community (of individuals with a shared interest) and practice (experiences and encounters that individuals share with their counterparts). Communities of practice build upon the characteristics of a working team or group - a number of people who are able to interact with one another, are psychologically aware of each other, and perceive themselves as members of a team or group. However, while they are often built from groups and 
group projects, communities of practice differ from groups in several ways; notably they aim to create an ongoing sense of community that all members invest in and contribute to, with shared values. We argue that communities of practice are important elements in professional development as they enable informal conversations about supervision to be part of a strategic approach to embedding reflexivity from a private practice to a communal one - being able to share and discuss one's own practice whilst maintaining the personal and individual focus through individual practitioner inquiries (Hill \& Vaughan, 2018).

In the case of the professional development of supervisors, we also encourage the use of more formal structures of learning such as workshops and mentoring schemes to provide support to those professionals who are less experienced (McCormack \& Pamphilon, 2004).

\section{Proposing a model for online and distance doctoral supervision development}

The professional development model has three dimensions based on the theories presented above: (i) workshops/courses/seminars - focused on more formal training and promoting instrumental, dialogic and self-reflective learning; (ii) a college of mentors focused on formal, dialogic and self-reflective learning; and (iii) an online community of practice - focused on informal, dialogic and self-reflective learning. These learning dimensions can occur in parallel or sequentially.

\section{Workshops/seminars or courses}

Formal modes of learning can occur, as previously explored in the literature, in different formats: workshops, seminars or courses/programmes. Independently of the format, we suggest a series of blended-learning opportunities to encourage supervisors to reflect and learn within the different environments. Learning is achieved through practice and through 'conversations' that learners engage in with themselves, and with their peers and teachers (Laurillard, 2002). Learners build their own concepts and revise them 
based on these 'conversations' and 'practices'. This dialogical process is easier to replicate in traditional $\mathrm{f} 2 \mathrm{f}$ environments. Guidance, instructions, feedback and assessment for understanding are core parts of the dynamics of a traditional $\mathrm{f} 2 \mathrm{f}$ environment and they are made available to learners implicitly. In an online setting, these actions, to some extent, need to be replicated through explicit narratives and activities. In online or distance supervision supervisors cannot supervise $\mathrm{PhD}$ candidates over a f2f 'coffee' (Hemer, 2012). They need to create more guidance, narratives and structure to guide online students in their research path. They should also ensure that synchronous and asynchronous communication channels are available to give prompt feedback as this will mitigate the sense of isolation that supervisees typically feel. In this environment, academics will experience learning in a formal setting, through dialogue and self-reflection. The content will address the pedagogy and challenges of distance supervision; and 'learning alliance', 'techne' and 'contextual experience' competencies, such as institutional regulations and procedures.

\section{College of mentors}

Academic development has long used mentoring as a strategy to promote collaboration and the exchange of practices between more and less experienced academics (McAlpine \& Winer, 2002). In our model we propose the development of a college of mentors, which aims at creating a safe collegial environment where more experienced supervisors mentor colleagues with less experience in distance supervision. The college intends to create a formal and dialogic environment where self-appointed or appointed supervisors can share their supervisory experiences in a $\mathrm{f} 2 \mathrm{f}$ environment, without feeling judged by their peers, and exchange supervisory experiences, which can be challenging for both parties. The role of the mentor can change to the one of the mentee and vice-versa, since the learning does not have roots in the level of seniority, or experience of the supervisor. The college of mentors intends to build a collaborative learning environment - a 'mentoring circle' - moving away from more traditional mentoring models where learning was seen as a means of transmitting knowledge from mentor to mentee and the partnership was often protective and paternalistic (Darwin \& Palmer, 2009). Independent of the seniority of the supervisors, each will play a leading 
role in reflecting on their experiences, anxieties and dilemmas, with the aim of learning from each other.

This formal environment needs to have a gatekeeper who is in charge of matching the supervisors, preparing the briefs to introduce the scheme and its advantages, and organising institutional events where supervisors can meet to discuss their experience. This college can be facilitated by Graduate Schools because of their privileged access to supervisors and their role in supporting the training of supervisors.

Due to the novelty of distance supervision, both the mentors and the mentees are still grasping the best approaches to supervising students at a distance and to creating a supervisory relationship built on trust. The college of mentors can also serve as an anchor for shadowing experiences. Shadowing in the workplace has proved to be very effective in medical learning environments (Kitsis \& Goldsammler, 2013). The observation of more experienced supervisors while supervising at a distance will be a valuable learning experience for more unexperienced supervisors because they will learn, in loco, the implicit and explicit supervisory approaches, roles, values and behaviours.

Although the structure of the college is formal, supervisors will be given the opportunity to self-reflect on their practice in an experiential environment and develop the professional work facets related to habits of mind and contextual expertise.

\section{On-line community of practice}

The informal online community proposed in this framework is intended to be used in conjunction with more formal learning as the latter will provide the learning structure and the former will provide opportunities for more informal discussion between users with shared interests.

The community of practice $(\mathrm{CoP})$ can include any supervisor who is interested in being part of this community, from the institution or outside. It intends to provide participants with the opportunity to start interacting with colleagues who they may not have met in person and, therefore, create a virtual encounter where they can interact with colleagues from other institutions or countries. This multicultural experience will allow them to expand their horizons, share habits and procedures and become more informal in their discussions with other supervisors that they may not have met before. 
This will ensure a safer and more collegial environment where supervisors will feel more open to sharing successful practices as well as facing the challenges of supervising at a distance.

In a CoP, members will be able to learn through practice, explore online tools, and experience communication challenges and ways to engage with content and learning. All of these features are relevant for those who are engaged in a distance supervision setting because online communities are a major feature of distance doctoral programme but their effectiveness in creating authentic learning communities of inquiry among students still requires deeper thinking. A study conducted by Crosta and colleagues (2015) found that distance doctoral students, engaged in a learning community of inquiry, were not always challenging each other's contributions and that a social presence seemed to be missing from the community. Therefore, we propose a model of an online community that engages supervisors to create a space for cognitive and social interactions based on Hoadley and Kilner's (2005) framework for communities of practice: (i) what do we want to share and discuss (content)?, (ii) how are we going to organise the dialogue? (conversation), (iii) how are we going to organise the groups inside the community and who will be the gatekeeper of the community? (connections), (iv) what is the context of this community (context), and (v) what do we plan to achieve with the community? (purpose). These five steps will help supervisors to organise and manage the community of practice.

In these CoPs supervisors can develop the five professional work facets as presented earlier in this paper, depending on their interests or needs. The facets are interrelated and can be developed over time and in different learning environments.

\section{Mode of delivery}

The rationale for this model rests on exposing distance supervisors to similar learning contexts to their students, making them explore different communication channels and learning at a distance, and ensuring that they are able to engage in conversations in an environment that they are comfortable with. This is why the mode of delivery of any continuous professional development offer needs to be clearly considered, since it will have an impact on how supervisors reflect on their learning. Evidence tells us that 
traditional $\mathrm{f} 2 \mathrm{f}$ sessions and group work are important for allowing supervisors to have the opportunity to learn from each other through a process of 'conversational enquiry' (Spiller et al., 2013).

We also believe that participants need to be confronted with the challenges of online education: the sense of isolation and belonging, translating materials to a new mode of delivery, managing students' expectations and online communication. All of the above are better understood when we experience them as learners and then link them to a supervisory experience. Thus, the more contact supervisors have with online learning encounters the better prepared they will be to replicate good practice in their supervisory strategies and the more capable they will be of responding to the challenges of distance supervision. Hence, there is an argument for delivering distance supervision professional development using both $\mathrm{f} 2 \mathrm{f}$ and distance encounters, and thus allowing participants to actively engage in activities online that force them to be confronted with, and reflect on the challenges of distance education, as well as to discuss their learning and shared practices in a more collegial and synchronous environment.

\section{Conclusion}

This paper explores the challenges of distance supervision, presents the relevance of professional development theories and proposes a model that can be used for continuous professional development for distance supervisors.

In conducting this study, we acknowledged that one of the biggest challenges for online and distance doctoral education is guaranteeing the quality of doctoral supervision (Suhonen \& Sutinen, 2014). Since most of the existing formal supervision development still consists, in many countries, of isolated workshops or seminars, we advocate the importance of institutions building a supportive environment where supervisors can professionally develop their knowledge and skills to supervise students and exchange experiences that can enrich their own understanding of how distance students learn. This is particularly relevant as evidence suggests that the number of distance doctoral programmes is increasing. We believe that the model suggested in this paper addresses these challenges and may be adopted by any HE institution that wants to provide better support to its distance supervisors. 
The model intends to be flexible and address the needs of distance supervisors by engaging them to build and advance knowledge in more formal learning environments and allowing them the 'freedom' to learn in informal environments with their peers. It is important to create an environment where supervisors can reflect on their learning experiences and their impact in practice. The model we propose will encourage institutions to reflect on how academics learn in professional settings, as well as the learning environments and the required competencies to be effective supervisors.

\section{Disclosure statement}

No potential conflict of interest was reported by the author.

\section{Notes on contributors}

\section{References}

Albion, P. R., \& Erwee, R. (2011). Preparing for doctoral supervision at a distance: Lessons from experience. In M. Koehler \& P. Mishra (Eds.), Proceedings of the Society for Information Technology \& Teacher Education International Conference (pp. 82-89). Association for the Advancement of Computing in Education (AACE) Press.

Ames, C., Berman, R., \& Casteel, A. (2018). A preliminary examination of doctoral student retention factors in private online workspaces. International Journal of Doctoral Studies, 13, 79-107.

Bolliger, D. U., Supanakorn, S., \& Boggs, C. (2010). Impact of podcasting on student motivation in the online learning environment. Computers \& Education, 55(2), $714-722$.

Crosta, L., Manokore, V., \& Gray, M. (2015). Do online cohorts evolve into authentic learning communities of inquiry? A case of the EdD cohort student in the EdD 
program. Proceedings of the 8th International Conference of Education, Research and Innovation (pp. 663-1673). IATED Press

Darwin, A., \& Palmer, E. (2009). Mentoring circles in higher education. Higher Education Research \& Development, 28(2), 125-136.

Erichsen, E. A., Bolliger, D. U., \& Halupa, C. (2014). Student satisfaction with graduate supervision in doctoral programs primarily delivered in distance education settings. Studies in Higher Education, 39(2), 321-338.

Evans, L. (2018). Implicit and informal professional development: What it 'looks like', how it occurs, and why we need to research it. Professional Development in Education, 5257, 1-14.

Halse, C., \& Malfroy, J. (2010). Retheorizing doctoral supervision as professional work. Studies in Higher Education, 35(1), 79-92.

Hemer, S. R. (2012). Informality, power and relationships in postgraduate supervision: Supervising $\mathrm{PhD}$ candidates over coffee. Higher Education Research and Development, 31(6), 827-839.

Hill, G., \& Vaughan, S. (2018). Conversations about research supervision - Enabling and accrediting a community of practice model for research degree supervisor development. Innovations in Education and Teaching International, 55(2), 153163.

Hoadley, C. M., \& Kilner, P. G. (2005). Using technology to transform communities of practice into knowledge-building communities. ACM SIGGroup Bulletin, 25(1), $31-40$.

Kaplan, R. E., Drath, W. H., \& Kofodimos, J. R. (1985). High hurdles: The challenge of executive self-development. Center for Creative Leadership Greensboro, NC.

Kitsis, E. A., \& Goldsammler, M. (2013). Physician shadowing: A review of the literature and proposal for guidelines. Academic Medicine, 88(1), 102-110.

Laurillard, D. (2002). Rethinking university teaching: A conversational framework for the effective use of learning technologies. EDUCAUSE review (2nd ed., Vol. 37). Routledge

Lave, J., \& Wenger, E. (1991). Situated learning: Legitimate peripheral participation. 
Cambridge University Press.

Loureiro, M. J., Huet, I., Costa, N., Baptista, A., \& Casanova, D. (2010). Using ICT to enhance the on-line research supervision process. Acta Academica Supplementum, $1,151-174$.

Maor, D., \& Currie, J. K. (2017). The use of technology in postgraduate supervision pedagogy in two Australian universities. International Journal of Educational Technology in Higher Education, 14(1).

Maor, D., Ensor, J. D., \& Fraser, B. J. (2016). Doctoral supervision in virtual spaces: A review of research of web-based tools to develop collaborative supervision. Higher Education Research \& Development, 35(1), 172-188.

Marsick, V. J. (1988). Learning in the workplace: The case for reflectivity and critical reflectivity. Adult Education Quarterly, 38(4), 187-198.

Marsick, V. J., \& Watkins, K. (2015). Informal and incidental learning in the workplace. Routledge.

McAlpine, L., \& Winer, L. (2002). Sustainable faculty development: An Indonesian case study. Innovations in Education and Teaching International, 39(3), 205-216.

McCormack, C., \& Pamphilon, B. (2004). More than a confessional: Postmodern groupwork to support postgraduate supervisors' professional development. Innovations in Education and Teaching International, 41(1), 23-37.

Mezirow, J. (1981). A critical theory of adult learning and education. Adult Education Quarterly, 32(1), 3-24.

Nasiri, F., \& Mafakheri, F. (2015). Postgraduate research supervision at a distance: A review of challenges and strategies. Studies in Higher Education, 40(10), 19621969.

Roumell, E. A. L., \& Bolliger, D. U. (2017). Experiences of faculty with doctoral student supervision in programs delivered via distance. Journal of Continuing Higher Education, 65(2), 82-93.

Sawyer, R. D. (2002). Situating teacher development: the view from two teachers' perspectives. International journal of educational research, 37(8), 733-753.

Singleton, H. W., \& Session, C. L. (2011). Faculty concerns related to distance learning 
within nontraditional doctoral programs. New Directions for Adult and Continuing Education, 2011(129), 31-41.

Spiller, D., Byrnes, G., \& Bruce-Ferguson, P. (2013). Enhancing postgraduate supervision through a process of conversational inquiry. Higher Education Research and Development, 32(5), 833-845.

Suhonen, J., \& Sutinen, E. (2014). The four pillar model - Analysing the sustainability of online doctoral programmes. TechTrends, 58(4), 81-88.

Wikeley, F., \& Muschamp, Y. (2004). Pedagogical implications of working with doctoral students at a distance. Distance Education, 25(1), 125-142.

Wisker, G., Robinson, G., \& Shacham, M. (2007). Postgraduate research success: Communities of practice involving cohorts, guardian supervisors and online communities. Innovations in Education and Teaching International, 44(2), 301320. 


\section{Exploring the professional development of online and distance doctoral} stpervisors

Authors:- ${ }^{*}$ Isabel Huet ${ }^{a}$ and Diogo Casanova ${ }^{b}$

a'ExPERT Academy, University of West London, St Mary's Road, London, W5. 5RF, UK https:Horcid.org/0000-0002-6215-0448.

b. ExPERT Academy, University of West London, St Mary's Road, London, W5. 5RF, UK https:/lorcid.org/0000-0002-8586-0370

Correspondent author: Isabel Huet: e-mail:isabel.huet@uwl.ac.uk; and phone number $+44(0) 2082312430$

Dr Isabel Huet is an Associate Professor in Higher Education Research and Academic Development at the University of West London, UK. She has nineteen years of teaching and research experience in $\underline{\text { Hhigher }}$ Education, including working at different Europeanbeen doing research in the areas of Doctorat Supervision, Pedagogy and Adult Learning Universities. She is the course leader for the Masters in Higher Education and responsible for the internationalisation and research/scholarship agenda of the Schoot.

Dr Diogo Casanova is an Associate Professor at the University of West London. His research addresses issues related with to the quality and design of online and blended learning courses and environments. Recently, he developed a particular interest in co designing with staff and students innovative learning spaces and environments with staff and students. 


\title{
Exploring the professional development of online and distance doctoral supervisors
}

\begin{abstract}
The sSupervision of doctoral students has been evolving in the last decade. Supervisors supervise students on campus or at a distance and supervision takes place in formal or informal environments with the latter occurring more often through online encounters. This context of supervision has changed supervisory practices and students' own approaches to learning. This paradigmatic shift demands a rethinking of how supervisors develop themselves and how they learn to cope with the challenges of 'modern' supervision. To date, little has been said or written about the development or training of doctoral supervisors who supervise students online or at a distance. This paper aims to fill this gap by presenting a model for the professional development offor supervisors in these contexts. This model can be adapted and implemented by institutions that wish to support supervisors who support students online or at the distance.
\end{abstract}

Keywords: doctoral supervision, distance and online supervision, professional development

Word count: $4929 \underline{4996}$

\section{Introduction}

In the UK, the USA and Australasia there has been an exponential growth inte online doctoral education, which is especially targeted atfor non-traditional students, such as working professionals, part-time students er and adult learners who cannot come regularly to the campus regularly (Albion \& Erwee, 2011). These programmes also have also-higher levels of attrition rates (Albion \& Erwee, 2011; Ames, Berman, \& Casteel, 2018), which require institutions to address the multidimensional factors that

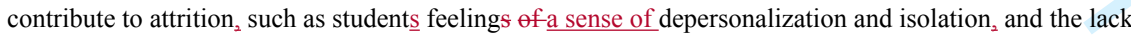
of collaborative learning environments (Ames et al., 2018). Arguably, online or distance supervision inevitably affects the way supervisors and students work, as well as their expectations, roles and responsibilities. This paradigmatic shift demands a rethinking of supervisory practices and the reconfiguration of the existing learning environments/spaces. In this context, it is urgent to rethink the professional development of supervisors, who, at some stage in the supervisor journey, need to supervise students online and at a distance.

To date, 1 Little has been said or written on the development or training of supervisors for online or distance supervision. Most of the literature onin the subject explores the role of, or approaches to supervision that takes place in more 'traditional' environments (Halse \& Malfroy, 2010; McCormack \& Pamphilon, 2004), where supervision occurs mainly throughonin face-to-face (f2f) encounters and where 
the student is physically located in the university. For this paper, we define distance doctoral supervision as a supervision process characterised by the research student and supervisor or tutor working at a distance mediated by learning technologies. The supervision is mediated by virtual learning environments where students and supervisors rely on the technology to communicate or build communities of practice, involving greater connectedness, collaboration and more intense relationships between themselves (Maor \& Currie, 2017) or within the wider academic community-(Loureiro, et al., 2010)(authers, 2010).

Although there is ancreasie ing demand for distance doctoral studies, educational research is raising questions about the quality and challenges of distance supervision (Erichsen, Bolliger, \& Halupa, 2014; Nasiri \& Mafakheri, 2015), and the training of supervisors (Halse \& Malfroy, 2010; Spiller, Byrnes, \& Bruce-Ferguson, 2013).

In this conceptual paper, we intend to explore the topic of distance research supervision and the challenges that supervisors face in their supervisory practices, as well as the theoretical foundations of adult learning theories, and provide a model for the professional development of distance doctoral supervisors.

\section{Distance research supervision}

Doctoral supervision is a traditional role in the profession, typically supported by the 'passing of the torch' method, which leads to supervision wisdom and is typically conducted intuitively by professors who mentor their PhD students in an apprenticeship model (Maor, Ensor, \& Fraser, 2016). Scholars often work collaboratively as part of research teams and, within their day-to-day routine, share their methods, findings and research outputs with their supervisors and fellow colleagues. Traditional supervision is done in a one-to-one relationship and in $\mathrm{f} 2 \mathrm{f}$ environments, albeit with an important community element between fellow researchers.

However, those working synergies have been challenged by the emergence of non-traditional doctorates targeted at to-non-traditional students, as referred to in the introduction. These doctorates can include accelerated programmes or professional doctorates delivered throughin blended learning or; flexible scheduling, or fully at a distance (Singleton \& Session, 2011). Technologies play i In this context technologies play a major role since they have becoame the vehicle for teaching and supervision. Technology is already having an impact on how doctoral research is conducted, whether on campus or at a distance, which is causing a set of challenges.

The first challenge in distance doctoral supervision is driven by space and temporal distance. The supervisor and supervisee may live on different continents and in different time zones, which may create issues with finding mutually convenient times to meet (Nasiri \& Mafakheri, 2015; Wisker, Robinson, \& Shacham, 2007) and even lead to a feeling of isolation or sense of loneliness for felt by both parties. This feeling of isolation may lead to a lack of focus, disconnectedness, a feeling of being unsupported, and too much reliance on the supervisor (Bolliger, Supanakorn, \& Boggs, 2010; Nasiri \& Mafakheri, 2015), contradicting a key objective of most postgraduate research, which is to promote 'independent research and critical thinking' (Nasiri \& Mafakheri, 2015, p. 1965). This leads us to a second challenge ${ }_{2}$ which is 
management of expectations and communication (Ames et al., 2018). As a result of the detachment caused by the distance it is likely that the supervisor will not know the supervisee before the supervision process starts and thus there is a strong need for further informal conversations to ensure that the environment is conducive to meaningful encounters. The challenge is therefore to create an environment where students can safely interact with their fellow students, agree methods of distance communication, and clarify forms of communication and learning expectations. This is essential for building trusting relationships, marked by high levels of professionalism. The communication challenges are often mitigated by increasing the number of videoconferencing meetings and the amount of individual support and by improving the community support aspects of the programme. The importance of developing online supervision communities has been strongly advocated by authors such as Crosta et. al (2015) and Wikeley and Muschamp (2004).

A third challenge relates to culture and language diversity.- Distance learning cohorts are typically more diverse in terms of nationalities, cultures, religions and languages so there is an expectation that there will beef some language and cultural barriers (Sussex, 2008; Wisker et al., 2007). Wisker, et al. (2007) argue that when not properly addressed, those cultural barriers may trigger misinterpretation and potentially clashes between the supervisor and the supervisee.

In summary, it is crucial for supervisors to understand the challenges, problems and pedagogical implications of working with doctoral students online or at a distance in order to build structures that support effective interactions and supervisor-supervisee relationships in virtual encounters (Roumell \& Bolliger, 2017; Wikeley \& Muschamp, 2004) and create connectedness between the distance doctoral student and the research community (Maor et al., 2016). Current supervisors may nhave never have experienced distance supervision or may have limited digital skills to work in and through virtual learning environments (Singleton \& Session, 2011) with students they have never met in person, and therefore requiringrequire "support in developing the range of skills appropriate to supervising doctoral students at a distance" (Albion \& Erwee, 2011, p.84). The traditional mode of supervision is being replaced by a new one that few have experienced or are comfortable with. The challenges presented here set the ground for the need for the professional development of supervisors, who must learn how to cope with these challenges.

\section{Professional development: theoretical foundations}

The purpose of professional development is to instigate learning. In Marsick's words, "learning is the way in which individuals or groups acquire, interpret, reorganize, change or assimilate a related cluster of information, skills and feelings" (1988, p. 88). It is also primary to the way in which "people construct meaning in their personal and shared organizational lives" (1988, p. 88). Many studies written in the 1980s reveal that a large percentage of learning takes place on-the-job rather than through formal training (Kaplan, Drath, \& Kofodimos, 1985). However, formalising learning is also important, as it provides structure and 'space' for academics to reflect and have discussions with each other. 
The model we propose is grounded in the theories of adult education and organisational learning such as Mezirow's transformative learning theory (1981), Halse and Malfroy's professional work facets's (2010) and Lave and Wenger's work on Communities of Practice (CoP) and situated learning (Lave \& Wenger, 1991) because these represent how learning should take place in the workplace. We believe that distance supervisors should learn in their professional settings by engaging with both formal and informal learning and by having the opportunity to reflect on and dialogue aboutdiscuss their work with their peers in a community of practice. Learning occurs when supervisors change or shape, for example, their own approaches to supervision or support student work. These are important elements of the theories presented below.

\section{Transformative learning theory}

The transformative learning theory accounts for the need to develop professional skills that are intertwined with organisational learning and self-reflection, as well asnd the-different forms of workplace learning, which are implicit and informal or situated and formal (Evans, 2018, Sawyer 2002). According to Evans (2018), -informal learning occurs when participants engage with "forms of professional learning and development that are not explicitly labelled or signposted as such" (p.6). Formal learning, on the other hand, is more explicit and usually takes place through formal training.

Mezirow (1981) identified three types of learning ${ }_{2} \div$ Instrumental, Dialogic and Self-reflective, that that should be considered in any form of professional development.

Instrumental learning refers to task-oriented problem solving, with a focus on technical learning where reflection is usually that of single cause-effect as in single-loop learning (Marsick, Watkins, \& Watkins, 2015). In this case, supervisors identify a problem, formulate a hypothetical course of action, try it out, observe the effects and evaluate the results. Learning is prescriptive and usually takes place in formal learning environments such as workshops and seminars.

Dialogic learning takes place in work settings where learners have the opportunity to question organisational norms and assumptions. Reflection is carried out critically as in double-loop learning learning includes active questioning about previously held beliefs or information.

Self-reflective learning is the way in which we learn to understand ourselves and is directed at personal change. The focus is on the development of supervisors' identity and role, and the need for self-change. Instrumental, dialogic and self-reflective learning cannot be easily separated and should be considered in terms of how academics learn in their professional settings.

\section{Five 'professional-Professional work' facets}

Halse \& Malfroy (2010) theorised the doctoral supervision process as professional work and, based on empirical analyses, developed a framework for the supervisory process. Labels were assigned to each facet to capture the substantive and theoretical features of the data in the following categories:

1. The learning alliance is the agreement between the supervisor and the student to work on a common goal, namely the production of a high-quality doctorate; in a distance education setting 
expectations are particularly relevant while negotiating goals and tasks. Here distance supervisors are expected to discuss how to reach a consensus and overcome barriers for timely completion.

2. Habits of mind refer to both a disposition and a mode of behaviour. They involve the capacity to learn and reflect on the principles for making particular decisions, and to exercise the judgment and disposition to apply these principles in unfamiliar or unforeseen situations in ethically appropriate ways. Habits of mind are necessary to ensure that supervisors are open to supervising and practising vivas and mock vivas in 'third spaces' and are willing to move away from their comfort zone in terms of supervision and $\mathrm{PhD}$ examinations.

3. Scholarly expertise is central to the work of doctoral supervision. Scholarly expertise, in this context, is the theoretical knowledge acquired through reflection and thinking. In this domain, it is important for supervisors to develop their knowledge around the context of distance doctoral education $_{2}$; theories of, and approaches to supervision ${ }_{i}$; the role of both the supervisor and the supervisee ${ }_{i}^{;}$, distance learning theories ${ }_{2}^{;}$; research ethics; and feedback on students' work.

4. Techne comprises the craft knowledge - technical skills or instrumental practice _-and the creative, productive use of expert knowledge to bring something into existence or accomplish a particular objective. Within the supervisory process, this knowledge can be combined in three areas: (i) what technical competencies and skills are needed by the students; (ii) when it is appropriate to use these skills; and (iii) why these skills are important; and the capacity to communicate these reasons to students.

5. Contextual expertise comprises an understanding of the contemporary climate of universities in relation to doctorates and doctoral education; the 'know- how' regarding access to the infrastructure and resources needed by students; a knowledge of faculty and university policies, procedures and requirements for each stage of the candidature; an understanding of the tensions between different approaches and methods in the production of a doctorate; and the capacity to advise students on how to traverse this complex territory.

These five facets are important key competencies in supervisors' development and should be included in any professional development course for distance supervisors.

\section{Communities of practice}

Communities of practice have been widely used in the professional development of academic staff and specifically supervisors (Hill \& Vaughan, 2018; Wisker et al., 2007). Communities of practice have been defined as groups of people who share a passion for certain topics and for deepening their expertise and knowledge through continuous interaction (Lave \& Wenger, 1991). A community of practice entails three key elements:- the domain (the topic that unites the community), the community (of individuals with a shared interest) and practice (experiences and encounters that individuals share with their counterparts). Communities of practice build upon the characteristics of a working team or group - a number of people who are able to interact with one another, are psychologically aware of each other, and perceive themselves as members of a team or group. However, while they are often built from groups and group projects, communities of practice differ from groups in several ways; notably they aim to create an 
ongoing sense of community that all members invest in and contribute to, with shared values. We argue that communities of practice are important elements in professional development as they enable informal conversations about supervision to be part of a strategic approach to embedding reflexivity from a private practice to a communal one - being able to share and discuss one's own practice - whilst maintaining the personal and individual focus through individual practitioner inquiries (Hill \& Vaughan, 2018).

In the case of the professional development of supervisors, we also encourage the use of more formal structures of learning such as workshops and mentoring schemes to provide support to those professionals who are less experienced (McCormack \& Pamphilon, 2004).

\section{Proposing a model for online and distance doctoral supervision development}

Based on the theories presented above $t$ The professional development model has three dimensions based on the theories presented above, covering both formal and informal learning and by developing different types of learning that allow supervisors to develop the five professional work facets: (i)

workshops/courses/seminars - focused on more formal training and promoting instrumental, dialogic and self-reflective learning; (ii) a college of mentors - focused on formal, dialogic and self-reflective learning; and (iii) an online community of practice - focused on informal, dialogic and self-reflective learning. These learning dimensions can occur in parallel or sequentially.

\section{Workshops/seminars or courses}

Formal modes of learning can occur, as previously explored in the literature, in different formats:- 0 f workshops, seminars or courses/programmes. Independently of the format, we suggest a series of blended-learning opportunities to encourage supervisors to reflect and learn within the different environments. Learning is achieved through practice and through 'conversations' that learners engage in with themselves, and with their peers and teachers (Laurillard, 2002). Learners build their own concepts and revise them based on these 'conversations' and 'practices'. This dialogical process is easier to replicate in traditional $\mathrm{f} 2 \mathrm{f}$ environments. Guidance, instructions, feedback and assessment for understanding are core parts of the dynamics of a traditional $\mathrm{f} 2 \mathrm{f}$ environment and they are made available to learners implicitly. In an online setting, these actions, to some extent, need to be replicated through explicit narratives and activities. In online or distance supervision supervisors cannot supervise $\mathrm{PhD}$ candidates over a f2f 'coffee' (Hemer, 2012). Supervisors-They need to create more guidance, narratives and structure to guide online students in their research path. They should also ensure that synchronous and asynchronous communication channels are available to give prompt feedback as this will mitigate the sense of isolation that supervisees typically feel. In this environment, academics will experience learning in a formal setting, through dialogue and self-reflection. The content will address the pedagogy and challenges of distance supervision; and 'learning alliance', 'techne' and 'contextual experience' competencies, such as institutional regulations and procedures.

\section{College of mentors}


Academic development has long been uusedsing mentoring as a strategy to promote collaboration and the exchange of practices between more experienced and less experienced academics (McAlpine \& Winer, 2002). In our model we propose the development of a college of mentors, which aims at creating a safe collegial environment where more experienced supervisors mentor colleagues with less experience in distance supervision. The college intends to create a formal and dialogic environment where selfappointed or appointed supervisors; can share their supervisory experiences in a $\mathrm{f} 2 \mathrm{f}$ environment ${ }_{2}$ without feeling judged by their peers, and exchange supervisory experiences, which can be challenging for both parties. The role of the mentor can change to the one of the mentee and vice-versa, since the learning does not have roots in the level of seniority, or experience of the supervisor. The college of mentors intends to build a collaborative learning environment - a 'mentoring circle' - moving away from more traditional mentoring models where learning was seen as a means of transmitting knowledge from mentor to mentee and the partnership was often protective and paternalistic (Darwin \& Palmer, 2009). Independent of the seniority of the supervisors, each will play a leading role in reflecting on their experiences, anxieties and dilemmas, with the aim of learning from each other.

This formal environment needs to have a gatekeeper who is in charge of matching the supervisors, preparing the briefs to introduce the scheme and its advantages, and organising institutional events where supervisors can meet to discuss their experience. This college can be facilitated by Graduate Schools because of their privileged access to supervisors and their role in supporting the training of supervisors.

Due to the novelty of distance supervision, both the mentors and the mentees are still grasping the best approaches to supervisinge students at a distance and to creatinge a supervisory relationship built on trust. The college of mentors can also serve as an anchor for shadowing experiences. Shadowing in the workplace has proved to be very effective in medical learning environments (Kitsis and Goldsammler, 2013). The observation of more experienced supervisors while supervising at a distance will be a valuable learning experience for more unexperienced supervisors because they will learn, in loco, the implicit and explicit supervisory approaches, roles, values and behaviours.

Although the structure of the college is formal, supervisors will be given the opportunity to self-reflect on their practice in an experiential environment and develop the professional work facets related to habits of mind and contextual expertise.

\section{On-line community of practice}

The informal online community proposed in this framework is intended to be used in conjunction with more formal learning as the latter will provide the learning structure and the former will provide opportunities for more informal discussion between users with shared interests.

The community of practice (CoP) can include any supervisor who is interested in being part of this community, and they can be-from the institution or from outside. It intends to provide participants with the opportunity to start interacting with colleagues who they may not have met in person, and, therefore, create a virtual encounter where they can interact with colleagues from other institutions or countries. This multicultural experience will allow them to expand their horizons, share habits and procedures and become more informal in their discussions with other supervisors that they may not have met before. This 
will ensure a safer and more collegial environment where supervisors will feel more open to sharing successful practices as well as facing the challenges of supervising at a distance.

In a CoP, members will be able to learn through practice, explore online tools, and experience communication challenges and ways to engage with content and learning. All of these features are relevant for those who are engaged in a distance supervision setting because online communities are a major feature of distance doctoral programme but their effectiveness in creating authentic learning communities of inquiry among students still requires deeper thinking. A study conducted by Crosta and colleagues (2015) found that distance doctoral students, engaged in a learning community of inquiry, were not always challenging each other's contributions and that a social presence seemed to be missing from the community. Therefore, we propose a model of an online community that engages supervisors to create a space for cognitive and social interactions based on Hoadley and Kilner's (2005) framework for communities of practice: (i) what do we want to share and discuss (content)?, (ii) how are we going to organise the dialogue? (conversation), (iii) how are we going to organise the groups inside the community and who will be the gatekeeper of the community? (connections), (iv) what is the context of this community (context), and (v) what do we plan to achieve with the community? (purpose). These five steps will help supervisors to organise and manage the community of practice.

In these CoPs supervisors can develop the five professional work facets as presented earlier in this paper, depending on their interests or needs. The facets are interrelated and can be developed over time and in different learning environments.

\section{Mode of delivery}

The rationale for this model rests on exposing distance supervisors to similar learning contexts to their students, making them explore different communication channels and learning at a distance, and ensuring that they are able to engage in conversations in an environment that they are comfortable with. This is why the mode of delivery of any continuous professional development offer needs to be clearly considered, since it will have an impact on how supervisors reflect on their learning. Evidence tells us that traditional $\mathrm{f} 2 \mathrm{f}$ sessions and group work are important for allowing supervisors to have the opportunity to learn from each other through a process of 'conversational enquiry' (Spiller et al., 2013).

We also believe that participants need to be confronted with the challenges of online education: the sense of isolation and belonging, translating materials to a new mode of delivery, managing students' expectations and online communication. All of the above are-is better understood when we experience them as learners and then link them to a supervisory experience. Thus, the more contact they supervisors have with online learning encounters the better they will be prepared they will be to replicate good practice in their supervisory strategies and the more capable they will be of responding to the challenges of distance supervision. Hence, there is an argument for delivering distance supervision professional development using both $\mathrm{f} 2 \mathrm{f}$ and distance encounters, and thus allowing participants to actively engage in activities online that force them to be confronted with ${ }_{2}$ and reflect on the challenges of distance education, as well as to discuss their learning and shared practices in a more collegial and synchronous environment. 


\section{Conclusion}

This paper explores the challenges of distance supervision, presents the relevance of professional development theories and proposes a model that can be used for modelling continuous professional development for distance supervisors.

In conducting this studystudy, we acknowledged that one of the biggest challenges for online and distance doctoral education is guaranteeing the quality of doctoral supervision (Suhonen \& Sutinen, 2014). Since most of the existing formal supervision development still consists, in many countries, of isolated workshops or seminars, we advocate the importance of institutions building a supportive environment where supervisors can professionally develop their knowledge and skills to supervise students and exchange experiences that can enrich their own understanding of how distance students learn. This is particularly relevant as evidence suggests that the number of distance doctoral programmes is increasing. We believe that the model suggested in this paper addresses these challenges and may be adopted by any HE institution that wants to provide better support to its distance supervisors.

The model intends to be flexible and address the needs of distance supervisors by engaging them to build and advance knowledge in more formal learning environments and allowing them the 'freedom' to learn in informal environments with their peers. It is important to create an environment where supervisors can reflect on their learning experiences and their impact in practice. The model we propose will encourage institutions to reflect on how academics learn in professional settings, as well as the learning environments and the required competencies to be effective supervisors.

\section{References}

Albion, P. R., \& Erwee, R. (2011). Preparing for doctoral supervision at a distance: Lessons from experience. Society for Information Technology \& Teacher Education International Conference, $82-89$.

Ames, C., Berman, R., \& Casteel, A. (2018). A preliminary examination of doctoral student retention factors in private online workspaces. International Journal of Doctoral Studies, 13, 79-107.

Bolliger, D. U., Supanakorn, S., \& Boggs, C. (2010). Impact of podcasting on student motivation in the online learning environment. Computers \& Education, 55(2), 714-722.

Crosta, L., Manokore, V., \& Gray, M. (2015). Do online cohorts evolve into authentic learning communities of inquiry? A case of the EdD cohort student in the EdD program. 8th International Conference of Education, Research and Innovation, 1663-1673.

Darwin, A., \& Palmer, E. (2009). Mentoring circles in higher education. Higher Education Research \& Development, 28(2), 125-136. 
Erichsen, E. A., Bolliger, D. U., \& Halupa, C. (2014). Student satisfaction with graduate supervision in doctoral programs primarily delivered in distance education settings. Studies in Higher Education, 39(2), 321-338.

Evans, L. (2018). Implicit and informal professional development: What it 'looks like', how it occurs, and why we need to research it. Professional Development in Education, 5257, 1-14.

Halse, C., \& Malfroy, J. (2010). Retheorizing doctoral supervision as professional work. Studies in Higher Education, 35(1), 79-92.

Hemer, S. R. (2012). Informality, power and relationships in postgraduate supervision: Supervising PhD candidates over coffee. Higher Education Research and Development, 31(6), 827-839.

Hill, G., \& Vaughan, S. (2018). Conversations about research supervision - Enabling and accrediting a community of practice model for research degree supervisor development. Innovations in Education and Teaching International, 55(2), 153-163.

Hoadley, C. M., \& Kilner, P. G. (2005). Using technology to transform communities of practice into knowledge-building communities. ACM SIGGroup Bulletin, 25(1), 31-40.

Kaplan, R. E., Drath, W. H., \& Kofodimos, J. R. (1985). High hurdles: The challenge of executive selfdevelopment. Center for Creative Leadership Greensboro, NC.

Kitsis, E. A., \& Goldsammler, M. (2013). Physician shadowing: A review of the literature and proposal for guidelines. Academic Medicine, 88(1), 102-110.

Laurillard, D. (2002). Rethinking university teaching: A conversational framework for the effective use of learning technologies. EDUCAUSE review (2nd ed., Vol. 37). London: Routledge

Lave, J., \& Wenger, E. (1991). Situated learning: Legitimate peripheral participation. Cambridge university press.

Loureiro, M. J., Huet, I., Costa, N., Baptista, A., \& Casanova, D. (2010). Using ICT to enhance the online research supervision process. Acta Academica Supplementum, 1, 151-174.

Maor, D., \& Currie, J. K. (2017). The use of technology in postgraduate supervision pedagogy in two Australian universities. International Journal of Educational Technology in Higher Education, $14(1)$.

Maor, D., Ensor, J. D., \& Fraser, B. J. (2016). Doctoral supervision in virtual spaces: A review of research of web-based tools to develop collaborative supervision. Higher Education Research \& Development, 35(1), 172-188.

Marsick, V. J. (1988). Learning in the workplace: The case for reflectivity and critical reflectivity. Adult Education Quarterly, 38(4), 187-198.

Marsick, V. J., \& Watkins, K. (2015). Informal and incidental learning in the workplace. London: Routledge.

McAlpine, L., \& Winer, L. (2002). Sustainable faculty development: An Indonesian case study. 
McCormack, C., \& Pamphilon, B. (2004). More than a confessional: Postmodern groupwork to support postgraduate supervisors' professional development. Innovations in Education and Teaching International, 41(1), 23-37.

Mezirow, J. (1981). A Critical theory of adult learning and education, Adult Education Quarterly, $32(1), 3-24$.

Nasiri, F., \& Mafakheri, F. (2015). Postgraduate research supervision at a distance: A review of challenges and strategies. Studies in Higher Education, 40(10), 1962-1969.

Roumell, E. A. L., \& Bolliger, D. U. (2017). Experiences of faculty with doctoral student supervision in programs delivered via distance. Journal of Continuing Higher Education, 65(2), 82-93.

Singleton, H. W., \& Session, C. L. (2011). Faculty concerns related to distance learning within nontraditional doctoral programs. New Directions for Adult and Continuing Education, 2011(129), $31-41$.

Spiller, D., Byrnes, G., \& Bruce-Ferguson, P. (2013). Enhancing postgraduate supervision through a process of conversational inquiry. Higher Education Research and Development, 32(5), 833-845.

Suhonen, J., \& Sutinen, E. (2014). The four pillar model - Analysing the sustainability of online doctoral programmes. TechTrends, 58(4), 81-88.

Sussex, R. (2008). Technological options in supervising remote research students. Higher Education, $55(1), 121-137$.

Wikeley, F., \& Muschamp, Y. (2004). Pedagogical implications of working with doctoral students at a distance. Distance Education, 25(1), 125-142.

Wisker, G., Robinson, G., \& Shacham, M. (2007). Postgraduate research success: Communities of practice involving cohorts, guardian supervisors and online communities. Innovations in Education and Teaching International, 44(2), 301-320. 